\title{
Intestinal infection of BALB/c mice with Yersinia enterocolitica 09 causes major modifications in phenotype and functions of spleen cells
}

\author{
Alfonso Ruiz-Bravo, Encarnación Moreno and María Jiménez-Valera
}

Author for correspondence: Alfonso Ruiz-Bravo. Fax: +34 958246235.

e-mail: aruizbr@platon.ugr.es

Departamento de Microbiologia, Facultad de Farmacia, Universidad de Granada, 18071 Granada, Spain

\begin{abstract}
Yersinia enterocolitica serotype 09 may cause a persistent intestinal infection with few or no symptoms in humans and in BALB/c mice. The present study demonstrated profound alterations in the immune status of BALB/c mice infected with $Y$. enterocolitica 09. Infected mice developed splenomegaly and phenotypic analysis of spleen cells revealed increases in $\mathrm{CD}^{+}$total $\mathrm{T}$ cells, $\mathrm{CD4}^{+}$helper T cells, CD8 ${ }^{+}$cytotoxic $\mathrm{T}$ cells and $\mathrm{CD} 11 \mathrm{~b}^{+}$phagocytic cells. Spleen cells from infected mice exhibited impaired responses to mitogens and suppressed the proliferation of normal splenocytes in response to mitogens. Suppression of responses to concanavalin A and heat-killed yersiniae was associated with increased production of gamma interferon and reactive nitrogen intermediates. $Y$. enterocolitica-infected mice resisted challenge with a lethal dose of the intracellular pathogen Listeria monocytogenes. These findings suggest that infection of mice with $Y$. enterocolitica 09 induces gamma-interferon-secreting cells that promote macrophage activation, mediating resistance to infection with $L$. monocytogenes, and macrophage production of reactive nitrogen intermediates, which results in in vitro inhibition of lymphocyte response to mitogens.
\end{abstract}

Keywords: Yersinia enterocolitica, gamma interferon, lymphocytes, macrophage activation

\section{INTRODUCTION}

Yersinia enterocolitica is a common cause of intestinal infections in humans (Cover \& Aber, 1989; Bottone, 1997). Extraintestinal and systemic infections are most often caused by strains belonging to so-called highvirulence serotypes, such as serotype $\mathrm{O} 8$ (Heesemann et al., 1993), although low-virulence serotypes, such as O3 and $\mathrm{O} 9$, may occasionally cause bactaeremia in patients with iron overload or other underlying diseases (Rabson et al., 1975; Bouza et al., 1980). The presence of a $70 \mathrm{~kb}$ plasmid (pYV) that carries a number of virulence genes is required for $Y$. enterocolitica strains to become virulent (Cornelis et al., 1998).

Non-septic sequelae of human yersiniosis include reactive arthritis, erythema nodosum, Reiter's syndrome,

Abbreviations: Con A, concanavalin A; HKY, heat-killed yersiniae; IFN- $\gamma$, gamma interferon. autoimmune thyroiditis and other immunopathological complications (Winblad, 1973; Bech et al., 1974; Toivanen et al., 1985). Alterations in the immune networks following infection with a number of microorganisms are likely to play a role in the genesis of immunopathological diseases (Schwartz, 1993). The effects of experimental yersiniosis on immunity parameters, such as the size of spleen cell subsets or the production of immune cytokines, have been documented in mice infected with serotype O8 strains (Autenrieth et al., 1994; Bohn et al., 1998). In comparison, lowvirulence serotypes have received little attention, although they possess immunomodulatory properties (Ruiz-Bravo et al., 1985, 1996). In humans, enteric colonization with low-virulence serotypes may persist for periods of up to 14 weeks without symptoms (Morris et al., 1991); however, there is no information available about the possible effects of the intestinal carriage of these strains on the immune condition of the hosts. In this study, we used a murine intestinal infection model (Ruiz-Bravo et al., 1999) to examine the immune status 
of mice infected with a low-virulence serotype of $Y$. enterocolitica.

\section{METHODS}

Mice. Six- to eight-week-old female BALB/c mice were provided by the Unit of Animal Experimentation, University of Granada (Granada, Spain). They were maintained under pathogen-free conditions.

Experimental infection with Y. enterocolitica. Strain IP383 of Y. enterocolitica was used in all experiments. It is a serotype O9 strain that carries the virulence plasmid pYV (Mazigh et al., 1983). Bacteria were grown on Tryptic soy agar (Difco) at $25^{\circ} \mathrm{C}$ for $24 \mathrm{~h}$, harvested, washed and resuspended in sterile water to obtain $10^{9}$ bacteria $\mathrm{ml}^{-1}$. Mice were infected via the oral route, as described previously (Ruiz-Bravo et al., 1999).

Phenotypic analysis of spleen cells. Spleens were homogenized in PBS containing 1\% (w/v) BSA (Sigma). Splenocytes were sedimented by centrifugation, resuspended in red blood cell lysing buffer (Sigma) for $10 \mathrm{~min}$, washed and resuspended in PBS containing BSA. Cell suspensions from individual mice were adjusted to $10^{7}$ viable cells $\mathrm{ml}^{-1}$. Aliquots $(100 \mu \mathrm{l})$ were incubated with $5 \mu \mathrm{l}$ fluorescein-isothiocyanate-conjugated monoclonal antibodies. The monoclonal antibodies used were anti-CD45R (clone RA3-6B2, which recognizes B lymphocytes), anti-CD3 (clone 29B, a pan T cell marker), anti-CD4 (clone H129.19, a marker for helper/inducer $\mathrm{T}$ cells and delayed hypersensitivity $\mathrm{T}$ cells), anti-CD8 (clone 53-6.7, a marker for cytotoxic T cells) and anti-CD25 (clone ATM-13, which recognizes the $\alpha$-chain of the IL-2 receptor complex in activated lymphocytes), purchased from Sigma; and antiCD11b (clone M1/70, which reacts with Mac-1 in macrophages and neutrophils), purchased fron Pharmingen. After a 60 min incubation at $4{ }^{\circ} \mathrm{C}$, cells were washed twice in PBS, fixed with $2 \%(\mathrm{v} / \mathrm{v})$ paraformaldehyde and kept in the dark until analysed by flow cytometry. Cell samples were analysed by using a FACS-Vantage flow cytometer (Becton Dickinson Immunocytometry Systems), with FACScan LYSIS II software for data acquisition. Data for 10000 cells were acquired.

Spleen cell proliferation assays. Spleens were removed aseptically and homogenized in sterile Hanks' balanced salt solution (Sigma). After erythrocyte lysis, splenocytes were washed and suspended in RPMI 1640 medium supplemented with $10 \%(\mathrm{v} / \mathrm{v})$ heat-inactivated fetal calf serum, $50 \mu \mathrm{M} \mathrm{2-}$ mercaptoethanol, $1 \mathrm{mM}$ sodium pyruvate, $2 \mathrm{mM}$ L-glutamine, penicillin $\mathrm{G}\left(100 \mathrm{U} \mathrm{ml}^{-1}\right)$, streptomycin $\left(100 \mu \mathrm{g} \mathrm{ml}^{-1}\right)$ and amphotericin B $\left(0 \cdot 25 \mu \mathrm{g} \mathrm{ml}^{-1}\right)$. All supplements and medium were from Sigma. Cell suspensions were distributed $\left(5 \times 10^{5}\right.$ cells per well) into 96-well tissue culture clusters with flatbottom wells (Costar). Salmonella typhi LPS (Sigma) was used at $2.5 \mu \mathrm{g} \mathrm{ml}^{-1}$ as a B-cell mitogen, and concanavalin A (Con A; Sigma) was used at $1 \mu \mathrm{g} \mathrm{ml}^{-1}$ as a T-cell mitogen. A preparation of heat-killed yersiniae (HKY) was obtained by heating cells of strain IP383 at $90^{\circ} \mathrm{C}$ for $15 \mathrm{~min}$ and used in proliferation assays at $10^{7}$ organisms $\mathrm{ml}^{-1}$. After incubation at $37^{\circ} \mathrm{C}$ in $5 \% \mathrm{CO}_{2}$ for $3 \mathrm{~d}$, proliferation of spleen cells was measured by colorimetric reading of 3-(4,5-dimethylthiazol-2yl)-2,5-diphenyltetrazolium bromide reduction, as described by Mosmann (1983).

Suppressor cell assay. Cells from the spleens of three uninfected or infected mice were pooled and were referred to as cell suspensions of control and infected mice, respectively. Suppressor cell activity was evaluated by coculturing spleen cells from control mice $\left(5 \times 10^{5}\right.$ per well $)$ with the cells tested for suppression $\left(10^{5}\right.$ per well), i.e. spleen cells from control or infected mice. Cultures with Con A or HKY were performed as outlined above. Lymphocyte proliferation was measured as described by Mosmann (1983).

Nitrite and gamma interferon assays. Spleen cells were cultured with LPS, Con A or HKY as described above. Supernatants were removed after $48 \mathrm{~h}$ for determination of nitrite levels, and after $72 \mathrm{~h}$ for quantification of gamma interferon $(\mathrm{IFN}-\gamma)$. Supernatants were stored at $-20^{\circ} \mathrm{C}$ until assayed. The nitrite concentration of the supernatants was measured by a standard Griess reaction adapted to microplates (Green et al., 1982); the absorbance at $550 \mathrm{~nm}$ was determined, with reference to a sodium nitrite standard curve. IFN- $\gamma$ was quantified by enzyme immunoassay (Endogen); the cytokine concentration was interpolated from the appropriate recombinant IFN- $\gamma$ standard curve.

Challenge with Listeria monocytogenes. A virulent isolate of L. monocytogenes was kindly provided by Dr De La Rosa (Hospital Virgende las Nieves, Granada, Spain). Bacteria were grown on blood agar at $37^{\circ} \mathrm{C}$ for $24 \mathrm{~h}$, harvested in sterile PBS, washed twice and $10^{3}$ organisms were injected into a mouse tail vein. Mice were observed daily and deaths recorded.

Statistical analysis. The differences between infected and control groups were analysed by using Student's $t$-test. A $P$ value of less than $0 \cdot 05$ was considered significant.

\section{RESULTS AND DISCUSSION}

\section{Effects of $Y$. enterocolitica infection on splenic cell phenotypes}

Mice developed splenomegaly after experimental infection with Y. enterocolitica O9 via the oral route. At 10 days after infection, the absolute number of nucleated cells in spleens from infected mice was significantly increased $(1.75$-fold, $P<0.025)$ compared with that in spleens from uninfected mice (Fig. 1). It has been

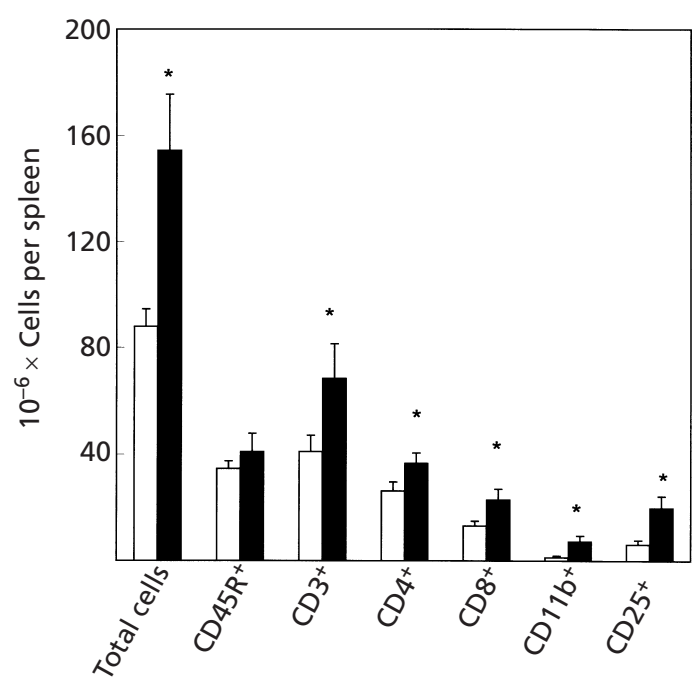

Fig. 1. Effect of $Y$. enterocolitica infection on spleen cell composition in BALB/c mice. Splenocytes were recovered from uninfected mice (open bars) and from 10-d-infected mice (solid bars) and analysed by flow cytometry. Results are means \pm SD from three mice and are representative of two separate experiments. Asterisks indicate that the differences with control mice are significant. 

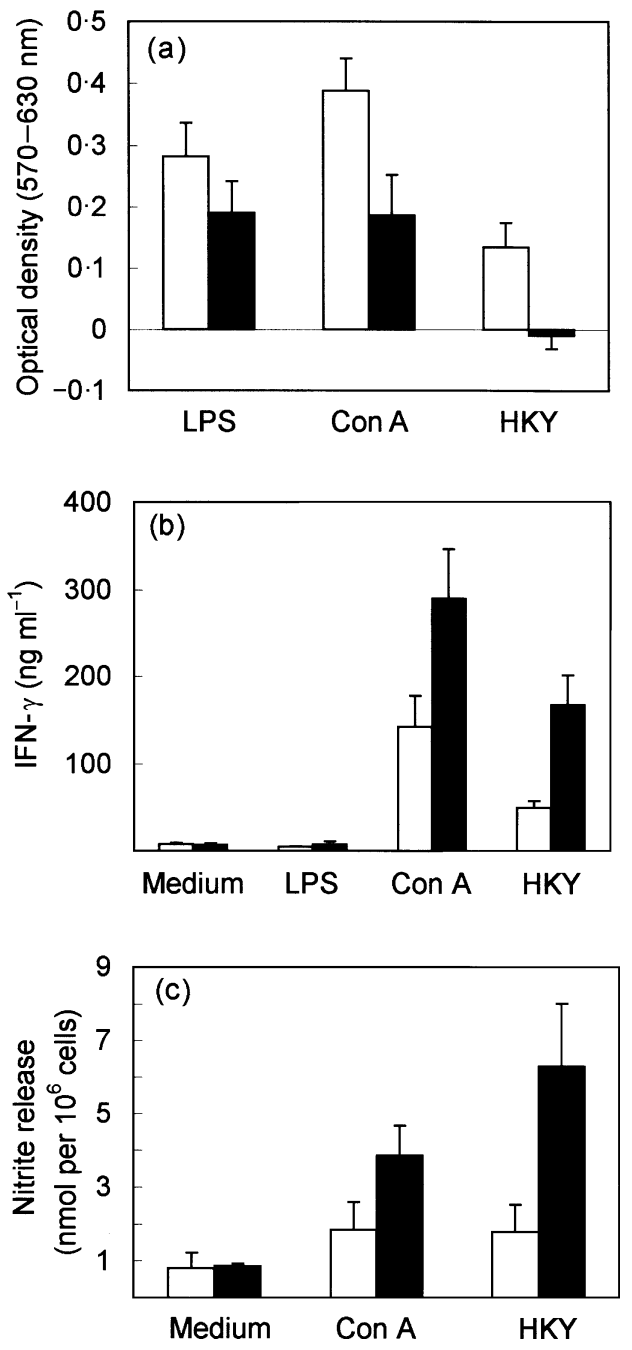

Fig. 2. Effect of $Y$. enterocolitica infection on the mitogeninduced responses of mouse splenocytes. Spleen cells $\left(5 \times 10^{5}\right.$ per well) from control (open bars) and from 10-d-infected mice (solid bars) were stimulated in vitro with LPS, Con A or HKY. (a) Spleen cell proliferation was assessed by colorimetric reading of 3-(4,5-dimethylthriazol-2-yl)-2,5-diphenyltetrazolium bromide reduction. Background values (wells with cells but no mitogen) were subtracted from all measures. Data are expressed as the mean $\pm S D$ of the mean for eight replicate wells from five mice. (b) Effect on IFN- $\gamma$ production by splenocytes. IFN- $\gamma$ levels were measured in supernatants by a specific immunoassay. (c) Effect on nitrite production by splenocytes. Nitrite levels were measured in supernatants by a standard Griess reaction. Results in (b) and (c) are means \pm SD from three mice.

reported that viable yersiniae may be recovered from spleens of mice infected with low-virulence strains by the oral route (Bakour et al., 1985). Therefore, an inflammatory reaction to bacterial components may be involved in splenomegaly development. However, in our assays, spleens from 10-d-infected mice were sterile, although recovery of yersiniae from faeces was always demonstrated (data not shown); this is in agreement with our previous description of the experimental infection of BALB/c mice with Y. enterocolitica O9 (Ruiz-Bravo et al., 1999).
Flow cytometry analysis of spleen cells revealed that the absolute numbers of $\mathrm{CD}^{+}$total $\mathrm{T}$ cells, $\mathrm{CD}^{+}$helper $\mathrm{T}$ cells, $\mathrm{CD}^{+}$cytotoxic $\mathrm{T}$ cells and $\mathrm{CD} 11 \mathrm{~b}^{+}$phagocytic cells were significantly increased $(1.7$-fold, $P<0.05 ; 1.4$ fold, $P<0.025 ; 1.7$-fold, $P<0.04$; and 5.6 -fold, $P<$ $0 \cdot 04$, respectively) in 10-d-infected animals (Fig. 1). The number of activated lymphocytes expressing the highaffinity interleukin 2 receptor $(C D 25)$ was also significantly increased ( $3 \cdot 2$-fold, $P<0 \cdot 025)$. The number of $B$ cells remained unchanged. However, the mean percentage of B cells decreased from $39.8 \%$ in uninfected mice to $26 \cdot 3 \%$ in infected mice. Percentages of total T cells and their helper and cytotoxic subsets were unaffected by infection, while the macrophage/ neutrophil population expanded from $1 \cdot 8 \%$ to $5 \cdot 1 \%$. It is interesting to note that C57BL/6 mice infected with $Y$. enterocolitica belonging to the high-virulence serotype O8 develop splenomegaly, whereas BALB/c mice do not develop splenomegaly (Autenrieth et al., 1994). In the present work, total cells, $\mathrm{CD} 4^{+} \mathrm{T}$ cells and $\mathrm{CD} 8^{+} \mathrm{T}$ cells were found to be increased in spleens from BALB/c mice infected with Y.enterocolitica $\mathrm{O} 9$, as in Y.enterocolitica O8-infected C57BL/6 mice (Autenrieth et al., 1994).

\section{Effects of $Y$. enterocolitica infection on the splenocyte responses}

We examined whether changes in spleen cell populations of infected mice were associated with modifications in the cell functions. The proliferative responses of spleen cells from 10-d-infected mice to LPS and Con A were decreased by $32.6 \%(P<0.025)$ and $52 \%(P<0.001)$, respectively, with regard to those of uninfected controls (Fig. 2a). HKY induced marked proliferation of spleen cells from control mice, but in 10-d-infected mice this response was abolished.

To investigate the possible presence of suppressor cells in spleens from Yersinia-infected mice, spleen cells from control and infected mice were placed in co-culture with spleen cells from control mice at a ratio of 1:5. The addition of spleen cells from infected mice reduced the response to Con A by $36 \%(P<0.002)$ and the response to HKY by $80 \%(P<0.0001)$ (data not shown).

IFN- $\gamma$ is a cytokine able to stimulate the macrophage production of reactive nitrogen intermediates (Drapier et al., 1988; Grazzinelli et al., 1992), leading to inhibitory effects on T cell proliferation (MacMicking et al., 1997). Thus, we investigated whether the suppression of lymphoproliferative responses of spleen cells from Yersinia-infected mice was associated with an increased production of IFN- $\gamma$. The results are shown in Fig. 2(b). Infection did not significantly affect the production of IFN- $\gamma$ by unstimulated (medium) or by LPS-stimulated cultures. However, Con A-stimulated cells from infected mice produced significantly higher levels of IFN- $\gamma$ than those from uninfected controls (mean increase of 2-fold, $P<0.03)$. In HKY-stimulated cultures, the production of IFN- $\gamma$ by cells from infected mice was also increased (3.4-fold, $P<0 \cdot 03$ ).

We also examined the nitric oxide synthesis in 


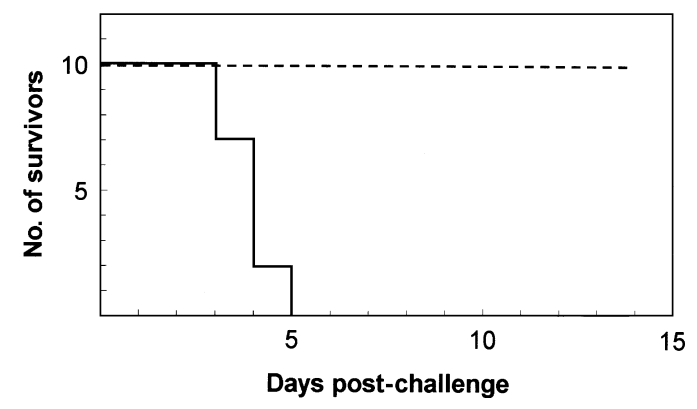

Fig. 3. Resistance of $Y$. enterocolitica-infected mice to the intracellular pathogen L. monocytogenes. Control mice (solid line) and 10-d-infected mice (broken line) were challenged via the intravenous route with $L$. monocytogenes $\left(10^{3}\right.$ organisms per mouse). Day 0 is the day of challenge with $L$. monocytogenes. The set of results presented is from one of three similar experiments.

splenocyte cultures, by determining the nitrite concentrations in the culture supernatants (Fig. 2c). Con Astimulated and HKY-stimulated cultures of spleen cells from Yersinia-infected mice contained significantly higher levels of nitrite than those from uninfected controls (mean increases of $2 \cdot 1$ - and $3 \cdot 5$-fold respectively, with $P$ values $<0.04$ for both stimuli).

Infection of C57BL/6 mice with Y. enterocolitica O8 results in IFN- $\gamma$ production by NK cells and $\mathrm{CD}^{+}$helper $\mathrm{T}$ cells, whereas this response is late and low in BALB/c mice (Autenrieth et al., 1994; Bohn \& Autenrieth, 1996). Previous studies showed that C57BL/6 mice are resistant to $Y$. enterocolitica $\mathrm{O} 8$, while $\mathrm{BALB} / \mathrm{c}$ mice are susceptible (Hancock et al., 1986). Our results suggest that low-virulence yersiniae are able to induce in BALB/c mice a response resembling that induced by highvirulence yersiniae in $\mathrm{C} 57 \mathrm{BL} / 6$ mice, but not in $\mathrm{BALB} / \mathrm{c}$ mice.

Our data have also shown that splenocytes from $Y$. enterocolitica O9-infected $\mathrm{BALB} / \mathrm{c}$ mice exhibited impaired responses to mitogens and significantly suppressed the ability of normal splenocytes to respond to mitogens. The marked splenomegaly and the increase in the number of interleukin 2 receptor-positive cells in the spleen suggest the presence of large numbers of in vivo activated lymphocytes which may be refractory to the in vitro overstimulation with mitogens. The inhibition of proliferative responses to Con A and HKY was associated with an increased production of IFN- $\gamma$ and reactive nitrogen intermediates. It has been documented that IFN- $\gamma$ is the most potent endogenous activator of the NO synthase gene in macrophages, and NO suppresses the proliferative response of lymphocytes (Albina et al., 1991; Candolfi et al., 1995).

\section{Resistance of $Y$. enterocolitica-infected mice to challenge with $L$. monocytogenes}

Production of reactive nitrogen intermediates by IFN- $\gamma$ activated macrophages correlates with resistance to microbial growth (MacMicking et al., 1997). To de- termine whether increased production of IFN- $\gamma$ and nitrite by splenocytes from Yersinia-infected mice in response to in vitro stimuli correlated with an increased resistance of mice against unrelated pathogens, we challenged animals with a lethal inoculum of L. monocytogenes. This intracellular pathogen causes a systemic infection in mice, and both IFN- $\gamma$-producing $\mathrm{T}$ cells and activated macrophages are required to overcome infection (Kaufmann, 1993; Unanue, 1997). As shown in Fig. 3, Yersinia-infected mice survived challenge by the intravenous route with a dose of L. monocytogenes that was lethal for $100 \%$ of control mice.

These results confirmed the presence of profound immunological alterations in a murine model for human infection with low-virulence serotypes of $Y$. enterocolitica. It will be interesting to determine the biological significance of these alterations in immunopathological disorders related to yersiniosis. Several hypotheses have been proposed to explain mechanisms for immunopathological sequelae of some infectious diseases: formation of immune complexes, alterations in the idiotypic networks, molecular mimicry, microbial superantigens and perturbations of the immune system (Schwartz, 1993). Previous studies with high-virulence strains of $Y$. enterocolitica $\mathrm{O} 8$ have provided evidence for some of these mechanisms: the production of factors with superantigenic activity on human $\mathrm{T}$ cells was shown to have been involved in the occasional development of autoimmune spondyloarthropathies in susceptible individuals following clearance of yersiniae (Stuart et al., 1995), and the presence of an envelope lipoprotein that is cross-reactive with the human thyrotropin receptor and activates human monocytes has been related to the induction of autoimmune hyperthyroidism (Zhang et al., 1997). Our results suggest that immunomodulation by low-virulence serotypes may be another mechanism involved in the genesis of some immunopathological sequelae of natural infections with $Y$. enterocolitica. There is evidence showing the importance of the interaction between $\mathrm{T}$ cells and macrophages in the pathogenesis of rheumatoid arthritis, with a central role for IFN- $\gamma$. This cytokine stimulates the overproduction of proinflammatory cytokines (Sebbag et al., 1997) and induces the arthritis-typical alterations in the profile of integrin expression by mononuclear phagocytes and synovial fibroblasts (Pirila \& Heino, 1996). Also, NO produced by IFN- $\gamma$-activated macrophages has been implicated in the pathogenesis of arthritis and other inflammatory diseases (Miyasaka \& Hirata, 1997).

\section{ACKNOWLEDGEMENTS}

The authors are grateful to Dr J. Lazuen for help with flow cytometry analysis. This work was supported by the Junta de Andalucia (Research Group CVI201).

\section{REFERENCES}

Albina, J. E., Abate, J. A. \& Henry, W. (1991). Nitric oxide production is required for murine resident peritoneal macrophages to suppress mitogen-stimulated $\mathrm{T}$ cell proliferation. Role 
of IFN-gamma in the induction of the nitric oxide-synthesizing pathway. J Immunol 147, 144-148.

Autenrieth, I. B., Beer, M., Bohn, E., Kaufmann, S. H. \& Heesemann, J. (1994). Immune response to Yersinia enterocolitica in susceptible BALB/c mice and resistant C57BL/6 mice: an essential role for gamma interferon. Infect Immun 62, 2590-2599.

Bakour, R., Balligand, G., Laroche, Y., Cornelis, G. \& Wauters, G. (1985). A simple adult-mouse test for tissue invasiveness in Yersinia enterocolitica strains of low experimental virulence. $J$ Med Microbiol 19, 237-246.

Bech, K., Larsen, J. H., Hansen, J. M. \& Nerup, J. (1974). Yersinia enterocolitica infection and thyroid disorder. Lancet 2, 951-952.

Bohn, E. \& Autenrieth, I. B. (1996). IL-12 is essential for resistance against Yersinia enterocolitica by triggering IFN-gamma production in NK cells and CD4 ${ }^{+} \mathrm{T}$ cells. J Immunol 156, 1458-1468.

Bohn, E., Schmitt, E., Bielfeldt, C., Noll, A., Schulte, R. \& Autenrieth, I. B. (1998). Ambiguous role of interleukin-12 in Yersinia enterocolitica infection in susceptible and resistant mouse strains. Infect Immun 66, 2213-2220.

Bottone, E. J. (1997). Yersinia enterocolitica: the charisma continues. Clin Microbiol Rev 10, 257-276.

Bouza, A., Dominguez, A., Meseguer, M., Buzon, L., Bioxeda, D., Revillo, M. J., De Rafael, L. \& Martinez-Beltran, J. (1980). Yersinia enterocolitica septicemia. Am J Clin Pathol 74, 404-409.

Candolfi, E., Hunter, C. A. \& Remington, J. S. (1995). Roles of gamma interferon and other cytokines in suppression of the spleen cell proliferative response to concanavalin A and toxoplasma antigen during acute toxoplasmosis. Infect Immun 63, 751-756.

Cornelis, G. R., Boland, A., Boyd, A. P., Geuijen, A., Iriarte, M., Neyt, C., Sory, M. P. \& Stainier, I. (1998). The virulence plasmid of Yersinia, an antihost genome. Microbiol Mol Biol Rev 62, 1315-1352.

Cover, T. L. \& Aber, R. C. (1989). Yersinia enterocolitica. N Engl J Med 321, 16-24.

Drapier, J. C., Wietzerbin, J. \& Hibbs, J. B. (1988). Interferon gamma and tumor necrosis factor induce the L-arginine dependent cytotoxic effector mechanism in murine macrophages. Eur J Immunol 18, 1587-1592.

Grazzinelli, R. T., Oswald, I. P., James, S. T. \& Sher, A. (1992). IL10 inhibits parasite killing and nitrogen oxide production by IFN$\gamma$-activated macrophages. J Immunol 148, 1792-1796.

Green, L. C. D., Wagner, D. D. A., Glogowski, J., Skepper, P. L., Wishnok, J. S. \& Tannenbaum, S. R. (1982). Analysis of nitrate, nitrite, and $\left[{ }^{15} \mathrm{~N}\right]$ nitrate in biological fluids. Ann Biochem 126, 131-138.

Hancock, G. E., Schaedler, R. W. \& MacDonald, T. T. (1986). Yersinia enterocolitica infection in resistant and susceptible strains of mice. Infect Immun 53, 26-31.

Heesemann, J., Gaede, K. \& Autenrieth, B. (1993). Experimental Yersinia enterocolitica infection in rodents: a model for human yersiniosis. APMIS 101, 417-429.

Kaufmann, S. H. E. (1993). Immunity to intracellular bacteria. In Fundamental Immunology, pp. 1251-1286. Edited by W. E. Paul. New York: Raven Press.

MacMicking, J., Xie, Q. \& Nathan, C. (1997). Nitric oxide and macrophage function. Annu Rev Immunol 15, 323-350.
Mazigh, D., Alonso, J. M. \& Mollaret, H. H. (1983). Simple method for demonstration of differential colony morphology of Yersinia enterocolitica. J Clin Microbiol 17, 555-557.

Miyasaka, N. \& Hirata, Y. (1997). Nitric oxide and inflammatory arthritis. Life Sci 61, 2073-2081.

Morris, J. G., Prado, V., Ferreccio, C., Robins-Browne, R. M., Bordun, A. M., Cayazzo, M., Kay, B. A. \& Levine, M. M. (1991). Yersinia enterocolitica isolated from two cohorts of young children in Santiago, Chile: incidence of and lack of correlation between illness and proposed virulence factors. J Clin Microbiol 29, 2784-2788.

Mosmann, T. (1983). Rapid colorimetric assay for cellular growth and survival: application to proliferation and cytotoxicity assays. J Immunol Methods 65, 56-63.

Pirila, L. \& Heino, J. (1996). Altered integrin expression in rheumatoid synovial lining type $B$ cells: in vitro cytokine regulation of alpha 1 beta 1 , alpha 6 beta 1 , and alpha v beta 5 integrins. J Rheumatol 23, 1691-1698.

Rabson, A. R., Hallet, A. F. \& Koornhof, H. J. (1975). Generalized Yersinia enterocolitica infection. J Infect Dis 131, 447-451.

Ruiz-Bravo, A., Jimenez-Valera, M., Alvarez de Cienfuegos, G., Ruiz, C., Kouwatli, K. \& Ramos-Cormenzana, A. (1985). Immunomodulation in mice by experimental infection with Yersinia enterocolitica. Microbiol Immunol 29, 1089-1097.

Ruiz-Bravo, A., Jimenez-Valera, M. \& Roman, S. M. (1996). Nonspecific modification of cellular immunity by Yersinia enterocolitica. Immunol Lett 49, 57-61.

Ruiz-Bravo, A., Moreno, E., Sampedro, A. \& Jimenez-Valera, M. (1999). Experimental infection of mice with Yersinia enterocolitica serotype $\mathrm{O} 9$ by oral and parenteral routes: spreading and enterotropism of virulent yersiniae. Curr Microbiol 38, 257-263.

Schwartz, R. S. (1993). Autoimmunity and autoimmune diseases. In Fundamental Immunology, pp. 1033-1097. Edited by W. E. Paul. New York: Raven Press.

Sebbag, M., Parry, S. L., Brennan, F. M. \& Feldmann, M. (1997). Cytokine stimulation of $\mathrm{T}$ lymphocytes regulates their capacity to induce monocyte production of tumour necrosis factor-alpha, but not interleukin-10: possible relevance to pathophysiology of rheumatoid arthritis. Eur J Immunol 27, 624-632.

Stuart, P. M., Munn, R. K., DeMoll, E. \& Woodward, J. G. (1995). Characterization of human T-cell responses to Yersinia enterocolitica superantigen. Human Immunol 43, 269-275.

Toivanen, A., Granfors, K., Lahesmaa-Rantala, R., Leino, R., Stahlberg, T. \& Vuento, R. (1985). Pathogenesis of Yersiniatriggered reactive arthritis: immunological, microbiological and clinical aspects. Immunol Rev 86, 47-70.

Unanue, E. R. (1997). Studies in listeriosis show the strong symbiosis between the innate cellular system and the T-cell response. Immunol Rev 158, 11-25.

Winblad, S. (1973). The clinical panorama of human yersiniosis. Contrib Microbiol Immunobiol 2, 129-132.

Zhang, H., Kaur, I., Niesel, D. W., Seetharamaiah, G. S., Peterson, J. W., Prabhakar, B. S. \& Klimpel, G. R. (1997). Lipoprotein from Yersinia enterocolitica contains epitopes that cross-react with the human thyrotropin receptor. J Immunol 158, 1976-1983.

Received 22 January 2001; revised 23 May 2001; accepted 10 July 2001. 